\title{
COVID-19 no Nordeste brasileiro: sucessos e limitações nas respostas dos governos dos estados
}

\author{
COVID-19 in Northeast Brazil: achievements and limitations \\ in the responses of the state governments
}

Ligia Kerr (https://orcid.org/0000-0003-4941-408X) ${ }^{1}$

Carl Kendall (https://orcid.org/0000-0002-0794-4333) 1,2

Antônio Augusto Moura da Silva (https://orcid.org/0000-0003-4968-5138) ${ }^{3}$

Estela Maria L Aquino (https://orcid.org/0000-0002-8204-1249) ${ }^{4}$

Julia M Pescarini (https://orcid.org/0000-0001-8711-9589) ${ }^{5}$

Rosa Lívia Freitas de Almeida (https://orcid.org/0000-0001-6423-543X) ${ }^{6}$

Maria Yury Ichihara (https://orcid.org/0000-0001-8590-6212) ${ }^{5}$

Juliane F Oliveira (https://orcid.org/0000-0002-7167-8754) ${ }^{5}$

Thália Velho Barreto de Araújo (https://orcid.org/0000-0001-9956-4145) ${ }^{7}$

Carlos Teles Santos (https://orcid.org/0000-0003-0970-0479) ${ }^{5}$

Daniel Cardoso Pereira Jorge (https://orcid.org/0000-0003-4707-3234) ${ }^{8}$

Demócrito de Barros Miranda Filho (https://orcid.org/0000-0003-2537-

$1476)^{7}$
Guilherme Santana (https://orcid.org/0000-0001-7860-2739) ${ }^{5}$

Ligia Gabrielli (https://orcid.org/0000-0002-5195-1979) ${ }^{4}$

Maria de Fatima Pessoa Militão de Albuquerque (https://orcid.org/00000002-4999-4160) ${ }^{9}$

Naomar Almeida-Filho (https://orcid.org/0000-0002-4435-755X) ${ }^{4}$

Natanael de Jesus Silva (https://orcid.org/0000-0003-3002-1032) ${ }^{5}$

Rafael Souza (https://orcid.org/0000-0002-0484-0782) ${ }^{5}$

Ricardo Arraes de Alencar Ximenes (https://orcid.org/0000-0002-9951$8840)^{7}$

Celina Maria Turchi Martelli (https://orcid.org/0000-0002-2491-0688) ${ }^{9}$ Sinval Pinto Brandão Filho (https://orcid.org/0000-0003-3768-2810) ${ }^{9}$ Wayner Vieira de Souza (https://orcid.org/0000-0002-0939-9332) ${ }^{9}$ Maurício Lima Barreto (https://orcid.org/0000-0002-0215-4930) ${ }^{5}$

\footnotetext{
${ }^{1}$ Programa de PósGraduação em Saúde Coletiva, Departamento de Saúde Comunitária, Faculdade de Medicina, Universidade Federal do Ceará. R. Professor Costa Mendes 1608, Bairro Rodolfo Teófilo. 60430140 Fortaleza CE Brasil. ligiakerr@gmail.com ${ }^{2}$ School of Public Health and Tropical Medicine, Tulane University. New Orleans LA USA.

${ }^{3}$ Departamento de Saúde Pública, Universidade Federal do Maranhão. São Luís MA Brasil.

${ }^{4}$ Instituto de Saúde Coletiva, Universidade Federal da Bahia (UFBA). Salvador BA Brasil.

${ }^{5}$ Centro de Integração de Dados e Conhecimentos para Saúde, Fundação Oswaldo Cruz (Fiocruz). Salvador BA Brasil. ${ }^{6}$ Programa de PósGraduação em Saúde Coletiva, Universidade de Fortaleza. Fortaleza CE Brasil.

${ }^{7}$ Faculdade de Ciências Médicas, Universidade Federal de Pernambuco. Recife PE Brasil.

${ }^{8}$ Instituto de Física, UFBA. Salvador BA Brasil.

${ }^{9}$ Instituto Aggeu Magalhães, Fiocruz. Recife PE Brasil.
}

Resumo No Brasil, a pandemia da COVID-19 tem sido severa nos estados das regiões mais pobres, como o Nordeste. A falta de politicas nacionais para controle da pandemia levou as autoridades estaduais e municipais a implementarem medidas de saúde pública. O objetivo deste estudo é mostrar o efeito dessas medidas na epidemia. A maior incidência da COVID-19 entre os nove estados do Nordeste foi registrada em Sergipe, Paraíba e Ceará. O Piauí, a Paraíba e Ceará foram os que mais testaram. Muitos estados apresentavam alta proporção de pessoas em trabalho informal. Estados com aeroportos internacionais tiveram importante papel na entrada e disseminação inicial do vírus, em especial o Ceará. Todos os estados aplicaram medidas de distanciamento social, proibição de eventos públicos e fechamento de unidades de ensino. As respostas foram o aumento significativo de distanciamento social, em especial Ceará e Pernambuco, a queda do número de reprodução (Rt) e a separação da curva dos casos observados da curva dos casos esperados sem as intervenções não medicamentosas em todos os estados. A pobreza, a desigualdade e as altas taxas de trabalho informal fornecem pistas do porquê da intensidade da COVID-19 na região. Por outro lado, as medidas de mitigação tomadas precocemente pelos governantes amenizaram os efeitos da pandemia.

Palavras-chave COVID-19, Nordeste Brasileiro, Prevenção e Controle 


\section{Introdução}

O Brasil atingiu a marca de 2.488 .807 casos de COVID-19 em 29 de julho de 20201. Sendo um país entre os mais desiguais do mundo, a pandemia da COVID-19 vem aprofundado essas desigualdades, não só produzindo um maior impacto em número de casos e óbitos nas regiões mais pobres, como o Norte e Nordeste, mas também promovendo o aumento da pobreza ${ }^{2-5}, \mathrm{o}$ crescimento das disparidades raciais e étnicas ${ }^{6} \mathrm{e}$ afetando de forma mais evidente as mulheres ${ }^{7,8}$.

A epidemia, apesar de não ter poupado as regiões mais ricas, vem ocorrendo de forma mais acentuada nos estados das regiões mais pobres, como o Norte e Nordeste. O Nordeste, uma das regiões mais pobres do país, representa $27 \%$ da população brasileira e apresenta cerca de um terço de todos os casos (34\%) e dos óbitos $(32 \%)^{1}$. Pesquisa sorológica em âmbito nacional mostrou uma notável variabilidade na prevalência dos anticorpos SARS-CoV-2 nas regiões brasileiras ${ }^{9}$, com taxas extremamente elevadas em cidades das regiões mais pobres. A pandemia do novo coronavírus tem sido um desafio para o Brasil pelas suas profundas desigualdades internas, conhecidamente associadas com a pandemia, nacional e internacionalmente.

$\mathrm{Na}$ ausência de tratamentos e vacinas, a única estratégia efetiva contra a COVID-19 é reduzir o contato entre pessoas suscetíveis e infectadas através da identificação precoce de casos ou redução do contato ${ }^{10}$, complementado com a limpeza de superfícies e mãos potencialmente contaminadas $^{11}$ e uso de mascaras ${ }^{12,13}$. A estratégia universalmente recomendada de testar casos e contatos e isolar os infectados foi muito timidamente praticada no Brasil. Na falta de políticas nacionais para o controle da pandemia, autoridades estaduais e municipais foram as responsáveis por implementar as medidas de saúde pública para reduzir a transmissão da COVID-19, inclusive declarando estado de emergência, determinando o fechamento de empresas de varejo e serviços, restringindo o transporte e fechando escolas e universidades ${ }^{14}$. As intervenções variaram substancialmente entre estados e municípios, tanto quanto às medidas que foram adotadas, quanto ao momento em que foram instituídas.

Os objetivos deste estudo são explorar a experiência da epidemia da COVID-19 na região nordeste e discutir as diferenças e similaridades entre os Estados desta região quanto ao comportamento da COVID-19, às medidas de distanciamento social implementadas e tentar compreender como essas diferenças podem ajudar a explicar os indicadores epidemiológicos da epidemia nesta região.

\section{Metodologia}

\section{Tipo e local de estudo}

Foi realizado um estudo misto, descritivo e analítico, na Região Nordeste do Brasil. Esta região é composta de nove estados (Alagoas, Bahia, Ceará, Maranhão, Paraíba, Pernambuco, Piauí, Rio Grande do Norte e Sergipe) e 1.793 municípios. Tem uma área aproximada de 1.5 milhões de $\mathrm{km}^{2}$ e 53 milhões de habitantes.

\section{Coleta de dados}

Os dados utilizados foram extraídos para cada estado das seguintes fontes: 1) dados demográficos e socioeconômicos do Instituto Brasileiro de Geografia e Estatística (IBGE) ${ }^{15} ; 2$ ) decretos federais e estaduais sobre as medidas de controle específicas para a COVID-19, sendo consideradas a data de vigência como o início do decreto; 3) número de casos e óbitos pela COVID-19 e outras Síndromes Respiratórias Agudas Graves (SRAG) provenientes do Ministério da Saúde e Secretarias Estaduais ${ }^{16,17}$ e Sistema Infogripe $\left.{ }^{18} ; 4\right)$ informações sobre chegada e saída de voos nacionais e internacionais da Agência Nacional de Aviação Civil (ANAC) ${ }^{19}$; e 5) dados de mobilidade do Google Mobility Report ${ }^{20}$ e do índice de isolamento social da agência Inloco ${ }^{21}$.

As iniciativas para desenvolvimento de medidas de mobilidade social vem sendo implementadas pela Google e pela empresa In Loco, a partir dos dados capturados por telefones celulares, com objetivo de auxiliar no enfrentamento da pandemia da COVID-19. O índice de isolamento social da empresa In Loco mostra o percentual diário da população que está atendendo à recomendação de distanciamento social nos estados e municípios brasileiros desde 01/02/202021. O Relatório de Mobilidade Comunitária da Google contém dados sobre visitas diárias aos seguintes locais: a) trabalho, b) parques, praias, praças e jardins, c) supermercados, drogarias e farmácias, d) restaurantes, shoppings, museus, bibliotecas e cinemas, e) estações metrô, trens e ônibus, e f) áreas residenciais. A movimentação das pessoas (visitas e tempo de permanência) em diferentes locais é estimada diariamente e comparada a uma linha de base, que corresponde à mediana 
de movimentação no período entre 3 de janeiro e 6 de fevereiro de $2020^{20}$. As mudanças de mobilidade são apresentadas em percentual e são calculadas diariamente até o dia 06 de maio de 2020 para os seis grupos. Abrange 132 países, inclusive o Brasil, e os dados estão disponíveis a partir de 26 de fevereiro. Para este trabalho, foi calculada a média da movimentação em áreas não residenciais (áreas a-e) e residenciais até o dia 13 de junho de 2020. O índice de isolamento social da empresa In Loco mostra o percentual diário da população que está atendendo à recomendação de distanciamento social nos estados e municípios brasileiros desde 01/02/202021.

Os dados sobre voos e passageiros foram coletados da ANAC e se referem às três capitais com aeroportos internacionais (Fortaleza, Recife e Salvador) e foram apresentados sob a seguinte forma: 1) número de pousos (entrando ou saindo) registrados entre as capitais referidas e São Paulo, Rio de Janeiro e o exterior por mês, independentemente da companhia aérea; 2) número de passageiros nestes voos; e 3) razão entre voos e passageiros por mês entre os percursos acima referidos.

\section{Análise}

Os dados coletados foram sumarizados na forma de tabelas e gráficos. Foi realizada análise pelo método qualitativo de comparação controlada ${ }^{22,23}$ entre os diferentes estados no Nordeste para discussão das diferenças e similaridades entre os estados.

O número de reprodução efetivo ao longo do tempo (Rt), o parâmetro de transmissão (Beta) e as curvas observada e predita do número acumulado de casos foram calculados em modelo compartimental, que subdivide a população entre suscetíveis, expostos (indivíduos em período de incubação), infectados assintomáticos, infectados sintomáticos e recuperados ${ }^{24,25}$. O valor de Rt diário é definido como o número médio de casos secundários infectados por um caso com início dos sintomas no dia " $t$ ", que na presente metodologia, leva em consideração também os casos secundários causados por infectados assintomáticos. O indicador pode ser interpretado como quanto maior o valor de Rt para determinado lugar, mais descontrolada a epidemia ${ }^{1}$.

\section{Resultados}

A Tabela 1 mostra os principais aspectos da epidemia da COVID-19 nos nove estados da região até o dia 21/07/2020. O estado onde foi observada a menor diferença entre o primeiro e o quinquagésimo e entre o primeiro e o centésimo caso foi o Maranhão. A maior incidência da COVID-19 entre os nove estados do Nordeste foi registrada em Sergipe (2049/100.000 hab.), seguido pela $\mathrm{Pa}$ raíba (1713/100.000 hab.) e Ceará (1677/100.000 hab.). O primeiro óbito oficial da região ocorreu em Pernambuco, em 25 de março. Até o dia 21 de julho, a razão entre o número de óbitos e o número de casos confirmados notificados pela COVID-19, foi mais alta em Pernambuco (7,6\%). A taxa de mortalidade pela COVID-19 foi maior no Ceará (80,1/100.000 hab.) seguido por Pernambuco (64,4/100,000 hab.). Em contraste, na Bahia, a razão entre o número de óbitos e o número de casos confirmados notificados pela $\mathrm{CO}$ VID-19 foi de 2,2\% e a taxa de mortalidade pela COVID-19 foi de 20,1/100.000 hab. A incidência de SRAG no Ceará atingiu 161,1/100.000 hab., seguido de 112,5/100.000 hab. em Pernambuco e de 97,8/100.000 hab. no Piauí, indicando que há grande quantidade de casos da COVID-19 que não estão sendo registrados como tal nesses estados, mesmo considerando a grande subnotificação e atraso de notificação de casos de SRAG ${ }^{26}$. A epidemia já alcançou 100\% dos municípios na maioria dos estados, sendo exceções a Bahia e o Piauí.

No tocante à testagem para identificação de casos ativos, o Piauí foi o estado nordestino que realizou mais testes a cada 100.000 habitantes (5.122), seguido pela Paraíba (4.954) e Ceará (4.219). A relação entre o número de testes realizados e o número de casos positivos foi maior no Piauí $(4,0)$, na Bahia $(2,9)$ e na Paraíba $(2,9)$, e menor em Alagoas $(2,0)$ e em Sergipe $(1,7)$. Essas relações baixas indicam que estão sendo testados quase que somente pessoas com alta probabilidade da doença, ou seja, os casos muito sintomáticos e os mais graves (Tabela 1 ).

A Tabela 2 apresenta alguns indicadores demográficos dos nove estados. A população dos estados varia entre 2,3 a 14,9 milhões de habitantes, em Sergipe e Bahia, respectivamente. Sergipe e Maranhão apresentam os menores percentuais de população idosa, com 60 anos ou mais. A densidade demográfica também mostra importantes diferenças, indo de 12,4 hab. $/ \mathrm{km}^{2}$ no Piauí a 112,3 hab. $/ \mathrm{km}^{2}$ em Alagoas. O Maranhão apresenta o percentual de quase $10 \%$ de adensamento 
excessivo de pessoas por quarto, que representa quase 2,5 vezes a mais que Bahia e Paraíba.

Usando o método da comparação controlada $^{22}$, a partir dos indicadores demográficos e socioeconômicos dos estados, foi elaborado um ranking preliminar da variável de resultado principal, o coeficiente do número de casos notificados acumulados de COVID-19 por 100.000 habitantes de cada estado. Em seguida, comparou-se este ranking com o ranking dos outros indicadores que correspondessem ou se aproximassem desta variável principal, observando as demais colunas das tabelas. Um dos indicadores, como o percentual de domicílios com adensamento excessivo, tem direta associação com a transmissão e quando há associação desses indicadores com a classificação inicial, sua seleção é lógica. Alguns dos outros indicadores já não têm esta associação direta. Por exemplo, o menor percentual de pessoas em trabalhos não tem uma relação direta com a transmissão. Esses indicadores representam uma variedade de diferentes fatores potenciais na transmissão: não apenas questões de exposição, mas também produtos de fatores contextuais, como distribuição de riqueza ou histórico de apoio político aos direitos dos trabalhadores. Esse padrão de classificação simétrica de indicadores pode ser complementado pela revisão das evidências acumuladas para cada estado. O Maranhão, por exemplo, é o estado que mais acumula estes indicadores associados negativamente com a saúde da população. Ceará tem um percentual importante da população abaixo da linha de pobreza, e em pobreza extrema, e tem menos domicílios servidos com abastecimento de água, indicadores esses importantes na determinação das doenças infecciosas. A maior incidência foi registrada no Ceará, seguido por Maranhão e Pernambuco. As maiores taxas de mortalidade também foram observadas nesses três estados.

$\mathrm{Na}$ Tabela 3, apresenta-se alguns indicadores socioeconômicos consagrados para a medir o grau de pobreza e as desigualdades. Nota-se importante similaridade entre os Índice de Desenvolvimento Humano (IDHs) dos estados nordestinos, destacando-se o Rio Grande do Norte, o Ceará e Pernambuco como aqueles que apresentam níveis um pouco mais elevados. A análise comparativa das desigualdades de renda, medidas através do Índice de Gini, também permite visualizar que estas são compartilhadas em níveis semelhantes por todos os estados, sendo um pouco mais acentuadas em Sergipe, Alagoas, Bahia e Ceará (esses dois últimos estados com valores mui- 
Tabela 2. Indicadores demográficos dos estados do Nordeste.

\begin{tabular}{|c|c|c|c|c|}
\hline Unidade Federativa & População $^{\mathrm{a}}$ & $\begin{array}{c}\text { \% pop. com } 60 \text { anos } \\
\text { ou }+^{b}\end{array}$ & $\begin{array}{c}\text { Densidade } \\
\text { Demográfica }^{c}\end{array}$ & $\begin{array}{c}\% \text { domicílios com } \\
\text { adensamento excessivo }^{\mathrm{d}}\end{array}$ \\
\hline Alagoas & 3.337 .357 & 14,7 & 112,3 & 5,8 \\
\hline Bahia & 14.873 .064 & 15,2 & 24,8 & 4,3 \\
\hline Ceará & 9.132 .078 & 15,2 & 56,8 & 6,3 \\
\hline Maranhão & 7.075 .181 & 12,5 & 19,8 & 9,9 \\
\hline Paraíba & 4.018 .127 & 14,8 & 66,7 & 4,3 \\
\hline Pernambuco & 9.557 .071 & 15,9 & 89,6 & 5,0 \\
\hline Piauí & 3.273 .227 & 15,6 & 12,4 & 4,6 \\
\hline Rio Grande do Norte & 3.506 .853 & 14,9 & 60,0 & 5,8 \\
\hline Sergipe & 2.298 .696 & 12,4 & 94,4 & 4,4 \\
\hline \multicolumn{5}{|c|}{$\begin{array}{l}\text { aBGE, População estimada, 2019: https://www.ibge.gov.br/cidades-e-estados, 'Projeção da população do Brasil e Unidades da } \\
\text { Federação por sexo e idade para o período 2010-2060. IBGE/Diretoria de Pesquisas. Coordenação de População e Indicadores } \\
\text { Sociais. Gerência de Estudos e Análises da Dinâmica Demográfica, 'Densidade demográfica: IBGE, Censo Demográfico } 2010 \text { : } \\
\text { https://www.ibge.gov.br/cidades-e-estados/al.html, dBGE, Pesquisa Nacional por Amostra de Domicílios Contínua } 2018 . \\
\text { Considera-se que há adensamento excessivo no domicílio em que há mais de } 3 \text { moradores por dormitório. }\end{array}$} \\
\hline
\end{tabular}

to semelhantes), e principalmente no Maranhão. De fato, o estado do Maranhão reúne os piores indicadores, apresentando o segundo pior IDH, a renda mensal domiciliar per capita mais baixa, os maiores percentuais de população abaixo da linha de pobreza e em pobreza extrema e a maior proporção de pessoas em trabalho informal. $\mathrm{O}$ Ceará apresenta o melhor IDH, mas tem o quarto pior rendimento domiciliar per capita, $42 \%$ da sua população vive abaixo da linha de pobreza; quase $2 / 3$ da sua população estava empregada na semana de referência, e perto de $30 \%$ tinha trabalho informal. Pernambuco ocupa o terceiro lugar em IDH e rendimento mensal domiciliar per capita. No entanto, $41 \%$ da sua população encontra-se abaixo da linha da pobreza, quase $2 / 3$ da sua população estava ocupada no final do 4 trimestre de 2019 , e quase $30 \%$ da população de 14 anos ou mais tinha trabalho informal (Tabela 3).

Ainda que todos os estados da região tenham muitos indicadores socioeconômicos desfavoráveis e características culturais comuns, eles apresentam diferenças que podem contribuir para distinguir a situação epidemiológica da COVID-19. Isso é possível visualizar na Tabela 3, que reúne alguns indicadores socioeconômicos consagrados para a análise do grau de pobreza e desigualdades. O Índice de Desenvolvimento Humano (IDH), por exemplo, é um indicador concebido pela Organização das Nações Unidas (ONU) para mensurar qualidade de vida e desenvolvimento econômico de uma população, utilizando na sua composição indicadores de educação (alfabetização e taxa de matrícula), longevidade (esperança de vida ao nascer) e ren- da (PIB per capita). Nota-se importante similaridade entre os IDHs dos estados nordestinos, destacando-se o Rio Grande do Norte, o Ceará e Pernambuco como aqueles que apresentam níveis um pouco mais elevados. A análise comparativa das desigualdades econômicas, medidas através do Índice de Gini, também permite visualizar que estas são compartilhadas em níveis semelhantes por todos os estados, sendo um pouco mais acentuadas em Sergipe, Alagoas, Bahia e Ceará (esses dois últimos estados com valores muito semelhantes), e principalmente no Maranhão. De fato, o estado do Maranhão reúne os piores indicadores, apresentando o segundo pior IDH, a renda mensal domiciliar per capita mais baixa, os maiores percentuais de população abaixo da linha de pobreza e em pobreza extrema e a maior proporção de pessoas em trabalho informal (Tabela 3 ).

A porta inicial de casos no país foi em São Paulo, cujo aeroporto principal (Guarulhos) apresenta enorme movimento de voos internacionais, nos quais aportaram pessoas vindas principalmente da Europa, que frequentemente embarcaram para outros destinos. Três capitais da região Nordeste - Fortaleza, Recife e Salvador - têm aeroportos internacionais. Além disso, em janeiro, cerca de metade dos 15.107 voos e 1.312.000 passageiros que aportaram na região Nordeste eram oriundos diretamente de São Paulo e, também, do Rio de Janeiro, onde a pandemia já se espalhava, face aos contaminantes vindos do exterior (Figura 1).

Outras formas de entrada da COVID-19 foram registradas de forma não sistemática. Por 
exemplo, eventos sociais, como um casamento amplamente noticiado na mídia e ocorrido em cidade balneário do sul da Bahia ${ }^{27}$, no qual participaram pessoas de várias origens e com histórico de viagens recentes a Europa, vários dos quais provavelmente infectadas com o SARS-CoV-2, contaminando outros participantes e trabalhadores. Estes ao se dispersarem, levaram o vírus para suas cidades de origem.

Os primeiros casos da COVID-19 identificados na região foram, de um modo geral, pessoas que haviam chegado de viagens ao exterior ou do Sudeste do país. As medidas de controle iniciaram-se pelo isolamento dos primeiros casos importados e pela quarentena de contatos, e foram seguidas pela proibição de eventos públicos e fechamento de unidades de ensino, adotadas por todos os governos estaduais. A implantação de cada medida de distanciamento social adotada nos estados do Nordeste foram, em sua maioria, realizadas em datas muito próximas, em meados de março ${ }^{14}$. Na Paraíba, os decretos implementando as medidas de distanciamento social foram promulgados um dia após a notificação do primeiro caso da doença (Quadro 1). Na Bahia, transcorreram-se onze dias até a promulgação de tais ações em nível estadual. Três estados - Maranhão, Rio Grande do Norte e Piauí - implementaram medidas de distanciamento social antes mesmo da confirmação do primeiro caso. O Maranhão foi também o primeiro estado do Nordeste a decretar o bloqueio total (lockdown em inglês), por 13 dias, a partir de 5 de maio de 2020, seguidos pelos estados do Ceará e Pernambuco.

A maioria dos estados adotou medidas que englobam diferentes esferas da vida social, incluindo a redução do tamanho ou proibição de eventos, fechamento de unidades de ensino (escolas e universidades), restrições ao funcionamento do comércio, serviços e indústria, fechamento e proibição de frequência a parques, piscinas e praias, redução do transporte (municipal, intermunicipal e interestadual) e mudanças no regime de trabalho de servidores públicos. A inexistência de legislação específica para o distanciamento social no nível estadual para cada medida considerada está destacada em cinza no Quadro 1. No entanto, é importante ressaltar que em capitais e muitos municípios, medidas foram também adotadas de acordo com o contexto epidemiológico e político de cada local.

A Figura 2 mostra a evolução da média da mobilidade fora da residência (coluna 1), o valor diário do número de reprodução efetivo ao longo do tempo - Rt (coluna 2) e as curvas de evolu- 

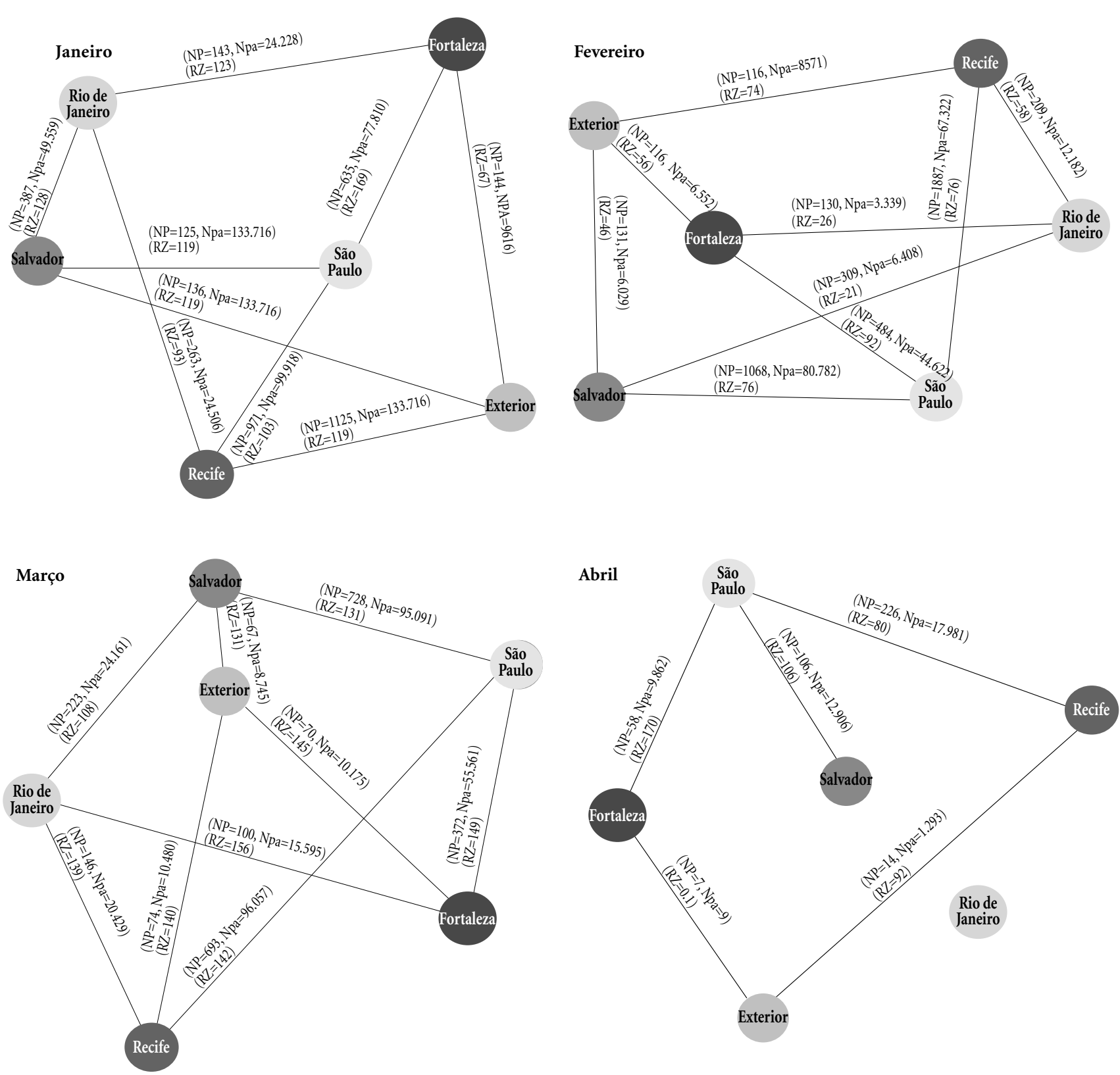

NP- Número de pousos

RZ- Razão de pouso

Figura 1. Número de pousos, número de passageiros e razão entre pousos e passageiros nos aeroportos internacionais dos estados do Nordeste provenientes do exterior e de outras cidades brasileiras São Paulo, Rio de Janeiro, com destino a Salvador, Fortaleza e Recife nos meses de janeiro a março de 2020.

ção do número acumulado de casos observados e estimados por um modelo SEIR (coluna 3) para os nove estados do Nordeste. Todos os estados apresentam reduções significativas de mobilidade fora do domicílio a partir da $2^{\mathrm{a}}$ quinzena de março. 


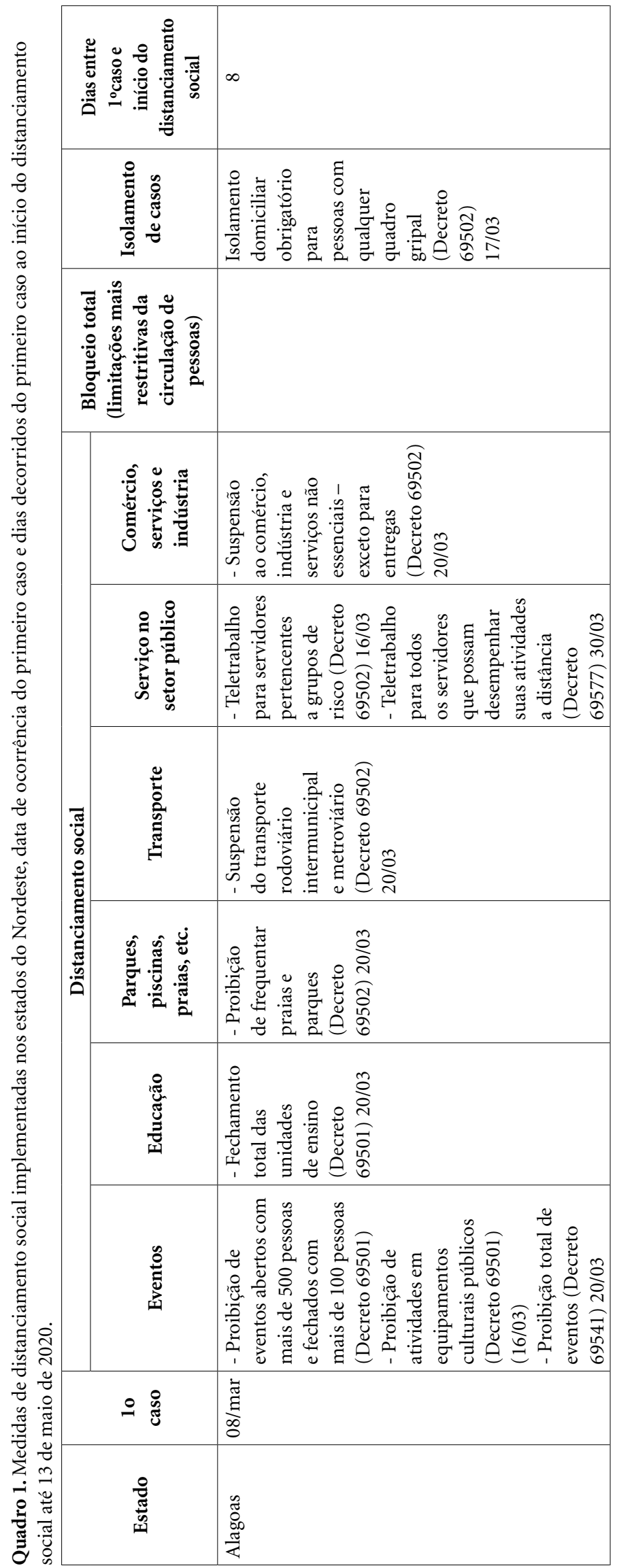




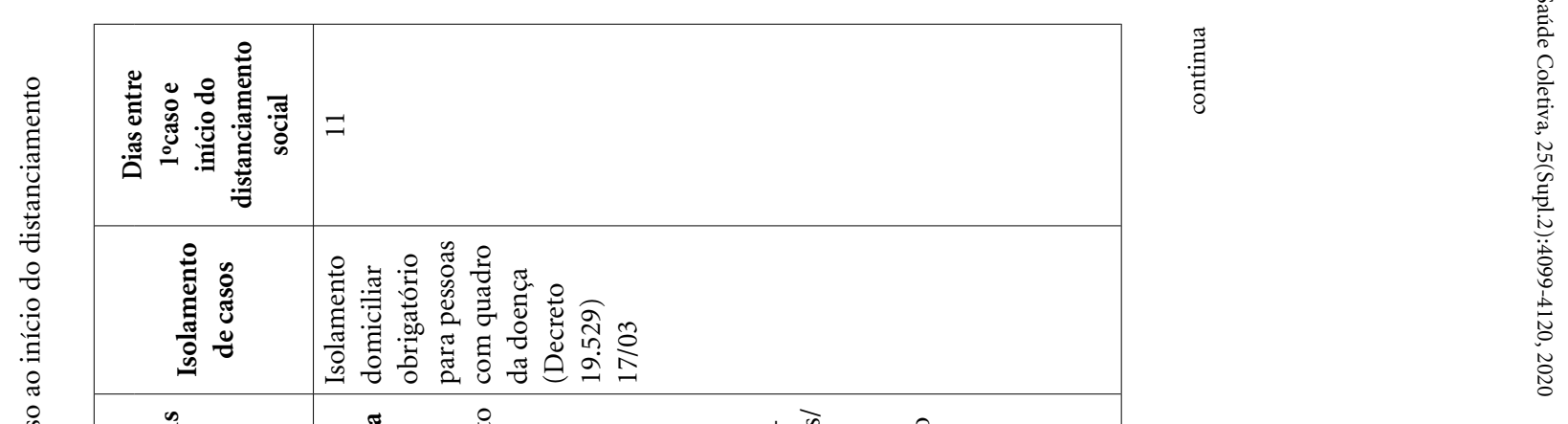




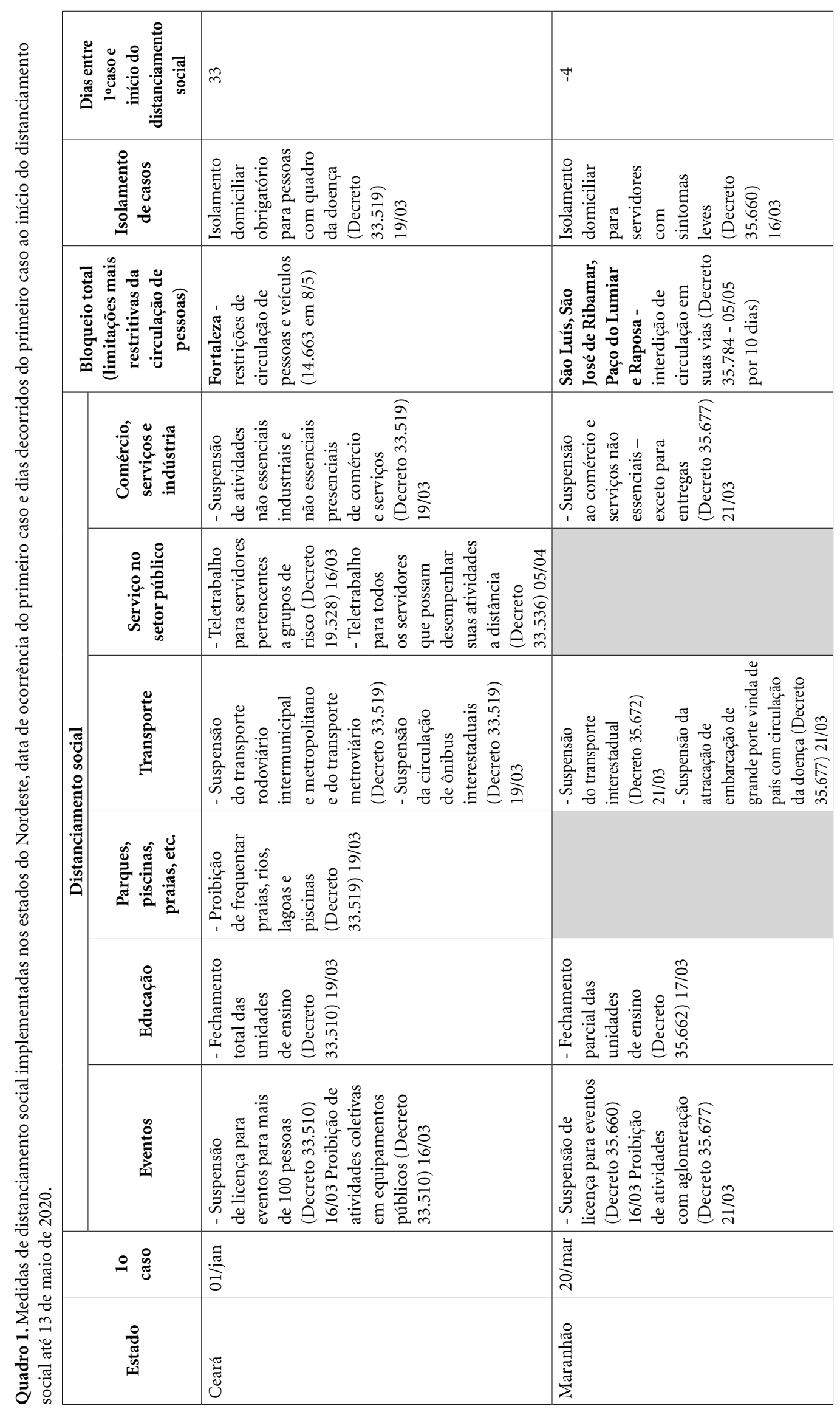




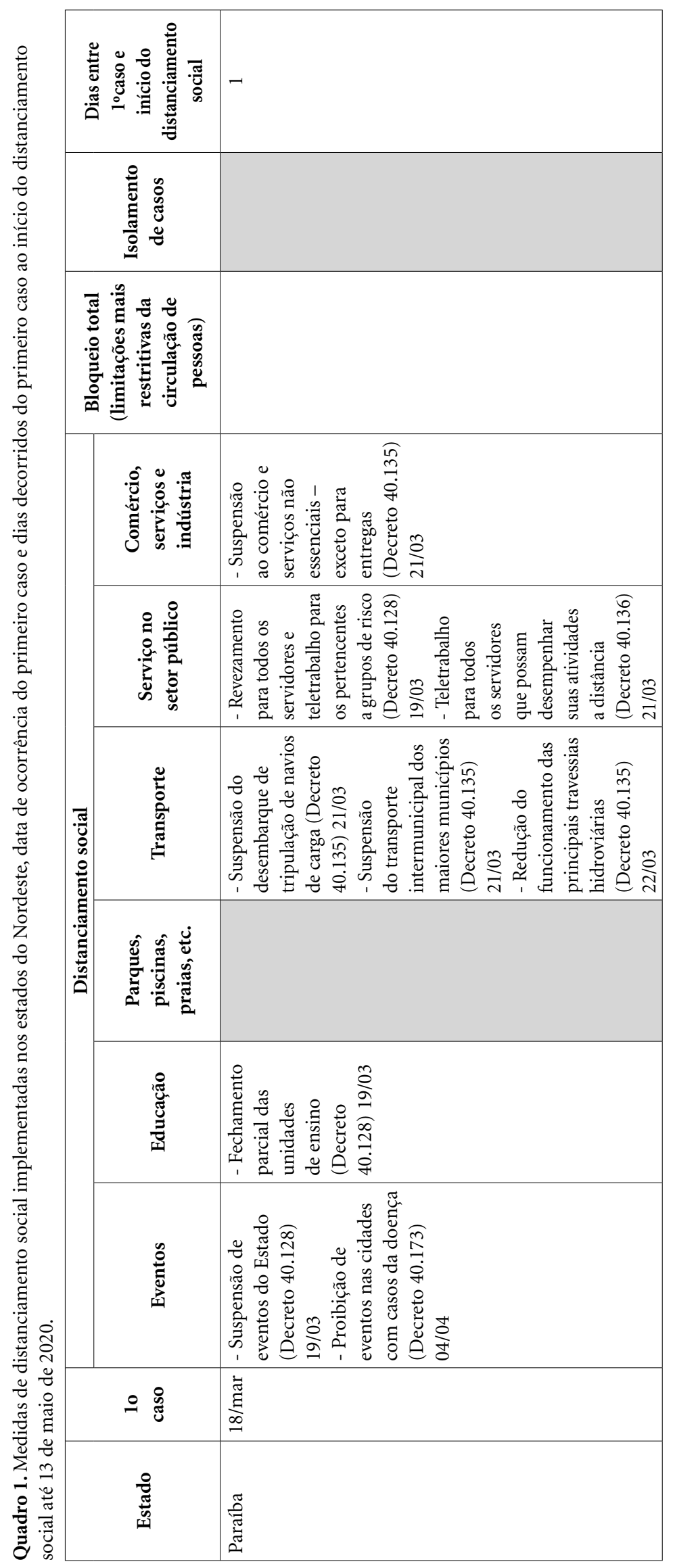




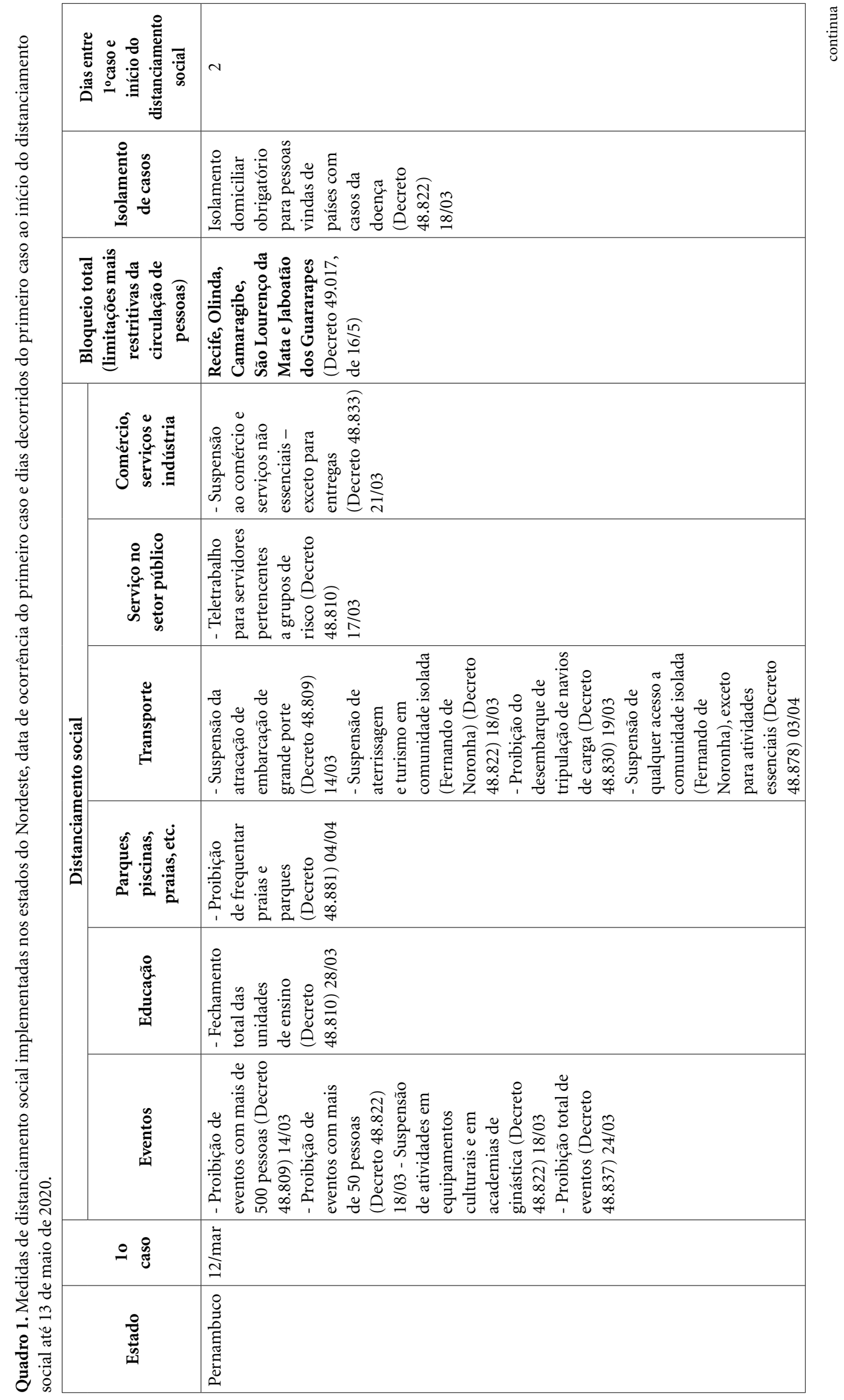




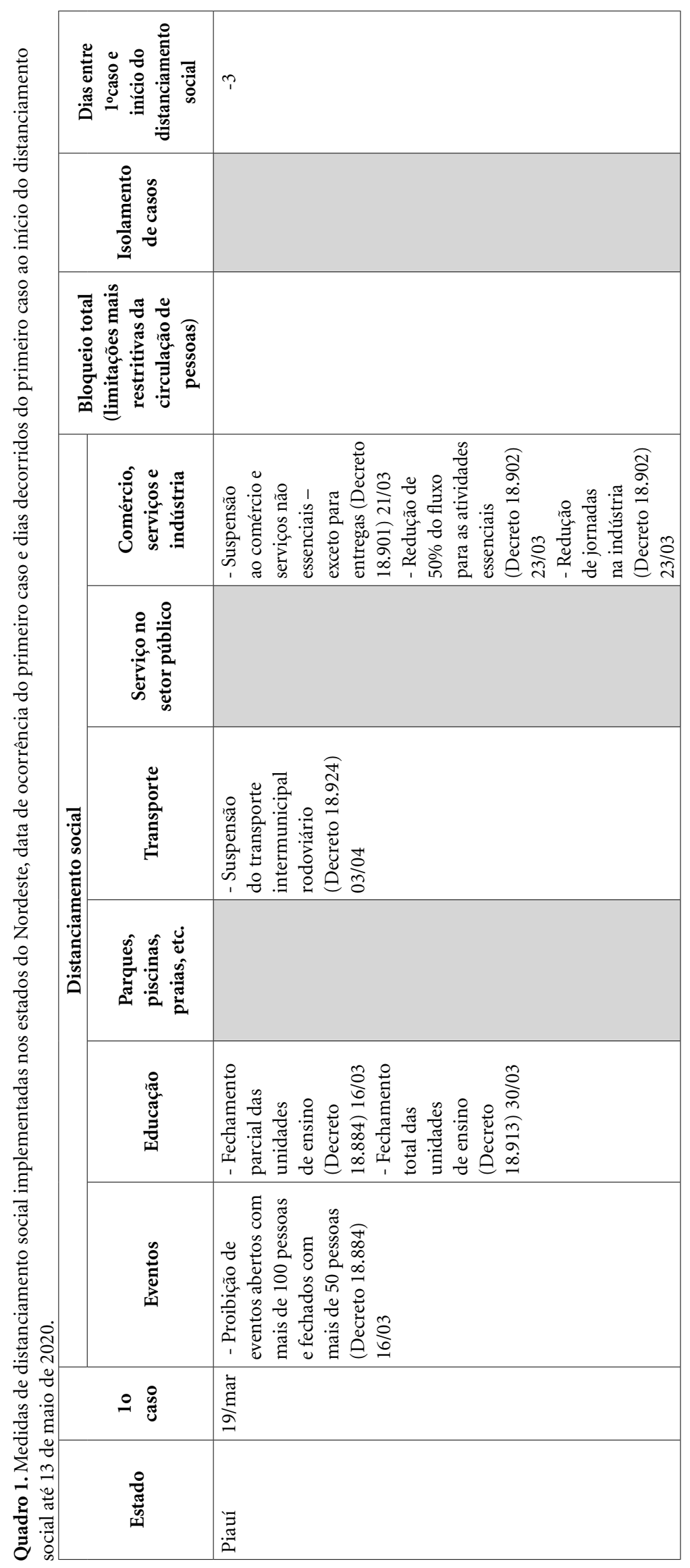




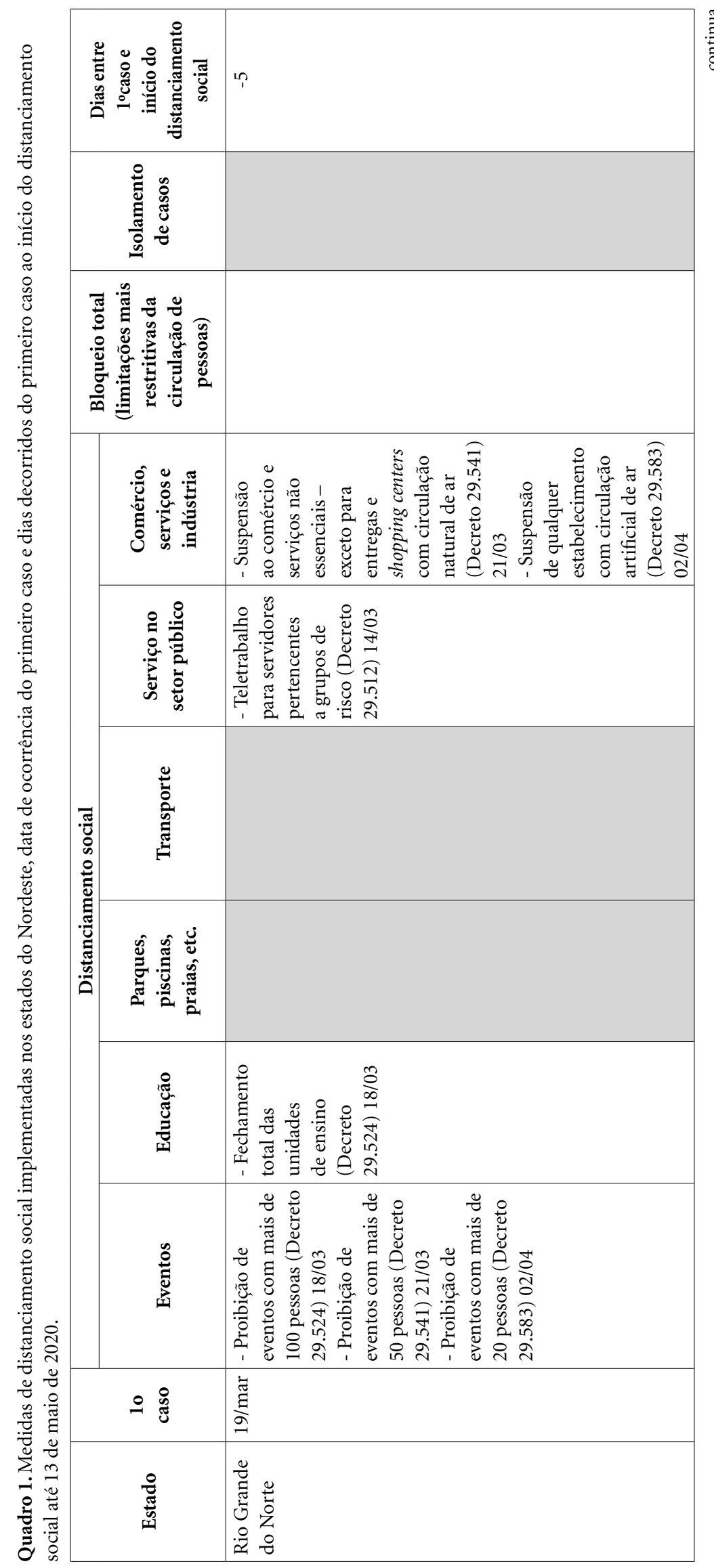




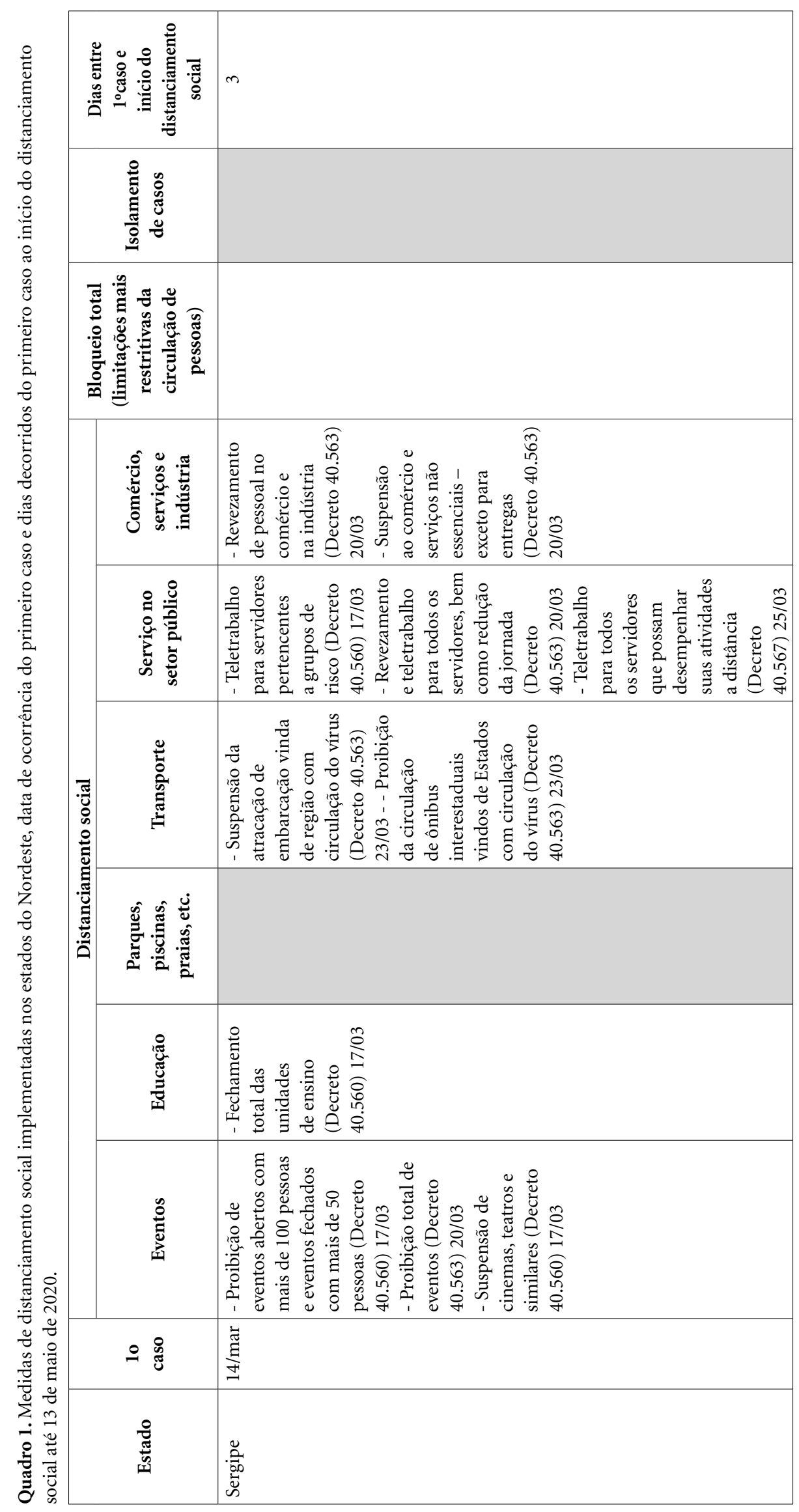




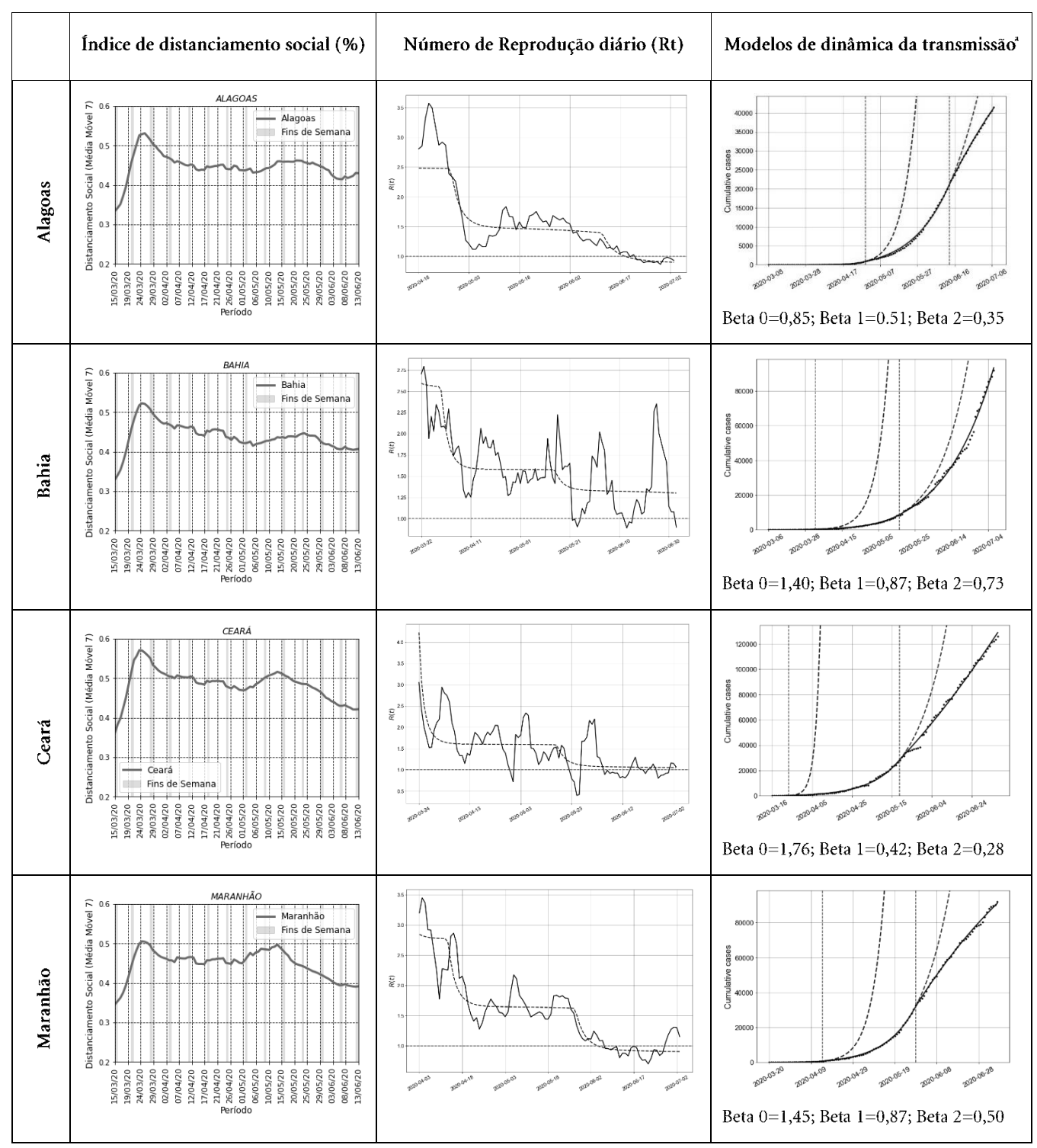

continua

Figura 2. Evolução do índice de mobilidade, do número efetivo de reprodução (Rt) ao longo do tempo, e do "efeito" das medidas de distanciamento social na dinâmica da transmissão da COVID-19, de março a junho de 2020.

A maioria dos estados manteve o índice de isolamento social (In Loco) acima de 40\%, porém registrou reduções a partir da $2^{\mathrm{a}}$ metade de maio. O Ceará, seguido do Pernambuco, foi o estado que apresentou as maiores taxas de distanciamento social, na maior parte do período estudado. O Maranhão, que implantou o lockdown no início de maio, manteve as taxas de iso- lamento social em patamar próximas das obtidas no início de implantação das medidas de distanciamento social, porem apresentou redução acentuada após ter suspenso o lockdown. (Figura 2, coluna 1).

Em todos os estados e no curso do período estudado, nota-se grande variabilidade do número de reprodução efetivo no tempo (Rt). Porém, 


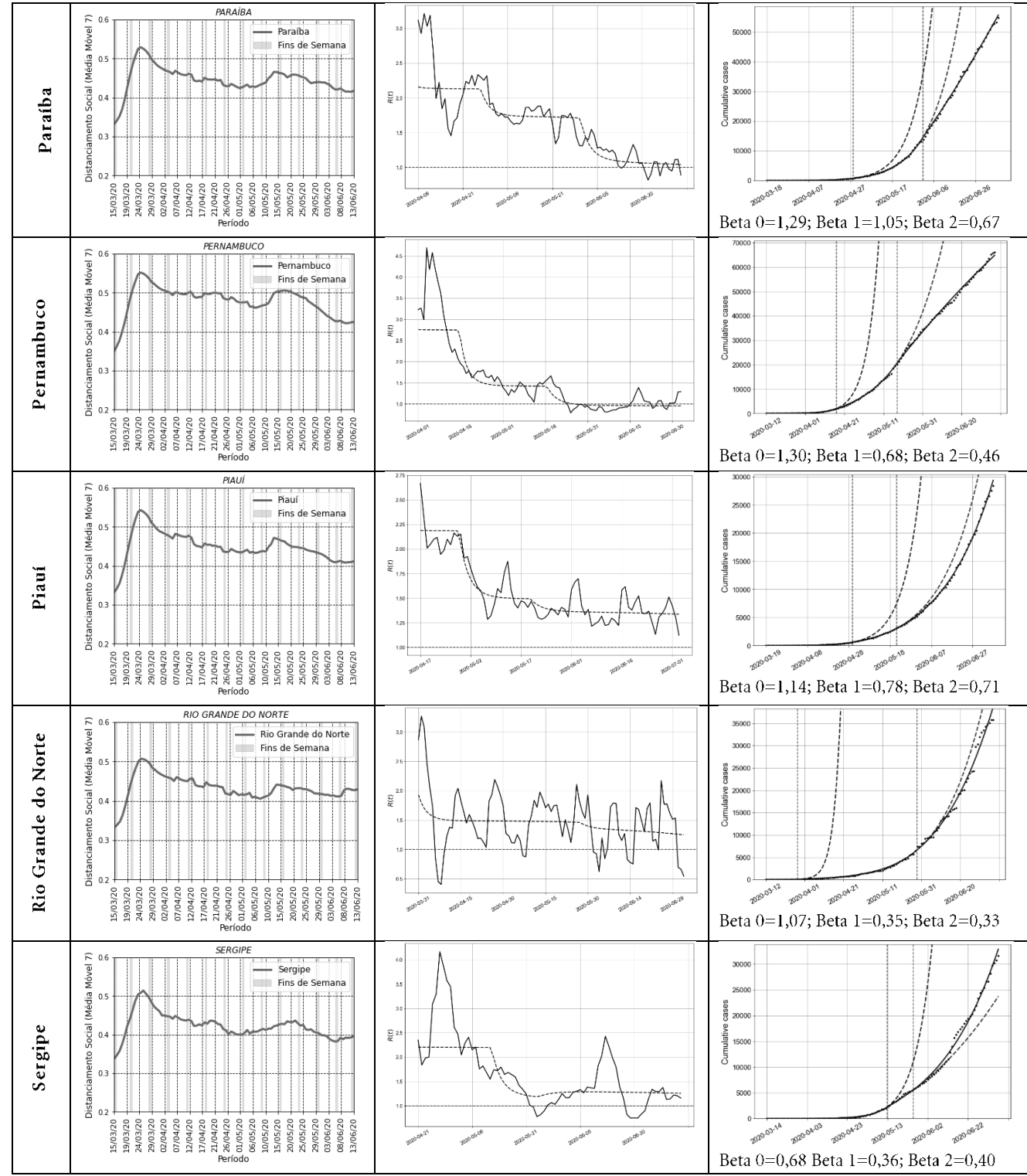

Figura 2. Evolução do índice de mobilidade, do número efetivo de reprodução (Rt) ao longo do tempo, e do "efeito" das medidas de distanciamento social na dinâmica da transmissão da COVID-19, de março a junho de 2020.

o número permaneceu acima de 1 na maior parte do tempo, exceto em alguns raros momentos em que ficou abaixo de 1 (Figura 2, coluna 2). No entanto, desde início de junho, os estados do Alagoas, Maranhão e Pernambuco têm apresentado Rt inferior. Destaca-se que o Ceará permanece ainda com valor de Rt médio acima de 1 .
Na Figura 2, coluna 3, a curva do número de casos acumulados registrados e a curva dos números obtidos pelo modelo permite também observar o possível efeito das medidas de distanciamento social em modificar as curvas. Assim, o estado da Bahia passou a distanciar-se do curso da curva de casos esperados sem intervenções 
não-medicamentosas no início de abril, quando o beta baixou de 1,40 para 0,87 . O Ceará foi o estado onde se observou também grande impacto das medidas de distanciamento social, visíveis no fim de março de 2020, com uma grande separação entre as curvas do número de casos esperados e observados. Nessa ocasião o beta caiu de 1,76 para 0,71. O Maranhão somente conseguiu reduzir os casos observados em relação aos esperados em meados de abril, cerca de 15 dias antes de decretado o lockdown (em 5/5/2020), quando o beta passou de 1.45 para 0,87 . Em uma nova forte redução, 15 dias após a decretação do lockdown, o beta passou de 0,87 para 0,50. Pernambuco deixou de seguir a curva prevista em torno do dia 15 de abril, quando os casos observados passaram a ser menores que os esperados, com redução do beta de 1,30 para 0,68. De forma geral, a curva dos modelos SEIR de todos os estados convergiram para uma redução da inclinação das curvas epidêmicas devido a diminuição do contato e transmissão da COVID-19, ocasionado pelas estratégicas de distanciamento social implementadas nesses estados.

\section{Discussão}

Este estudo mostra que a COVID-19 tem impactado a região Nordeste de forma muito severa. A falta de liderança do governo em formular uma resposta nacional consistente, levou a governos dos estados e administrações municipais a tomarem em suas mãos as decisões de responder à epidemia e as medidas para mitigá-la. Este estudo focando nos estados da região Nordeste, uma das regiões mais pobres do país, mas heterogênea em alguns indicadores socioeconômicos e demográficos, permite verificar as variações na magnitude da epidemia e explorar a efetividade das medidas de distanciamento social implementadas em um contexto socioeconômico e político desfavorável.

A interação entre pobreza, desemprego, nível de escolaridade, raça, gênero e cor têm sido documentadas como determinantes da COVID-1928,29. Populações com baixa renda são mais expostas à contaminação por doenças infecciosas, incluindo pelo SARS-CoV-2, devido à falta de acesso a saneamento básico e à água tratada, à falta de acesso à educação e aos serviços de saúde, ao uso de transportes públicos sujeitos à aglomerações e à dificuldade de realizarem o isolamento, por morarem em residências precárias e/ou com um número excessivo de moradores, ou também por estarem mais frequentemente desempregadas ou engajadas em empregos informais. O Brasil iniciou a epidemia com $41 \%$ de trabalhadores informais, ou seja, sem direitos sociais, como abono desemprego, férias, licença gestante e previdência. Não por acaso, os nove estados do Nordeste estão entre os 12 estados brasileiros com menores rendimentos efetivamente recebido pela população pesquisada na PNAD contínua de maio de $2020^{30}$. Essa mesma pesquisa mostrou que as taxas de desocupação aumentaram em 12 estados brasileiros, metade dos quais estão na região Nordeste, e quatro destes seis estão entre os que apresentaram as maiores taxas de desocupação do país. Em dois destes estados em que a taxa de desocupação aumentou (Maranhão e Ceará), e em Pernambuco, que já tinha alta taxa, maior que o Ceará, apresentaram também as maiores taxas de casos notificados pela COVID-19. Taxas altas de desocupação ou trabalho informal, sem assistência do governo em apoiar famílias com uma renda especial, levam à busca diária por uma renda e, consequentemente, à baixa adesão às medidas de distanciamento social, refletindo em altas taxas de transmissão da doença ${ }^{14}$. O distanciamento social não só demora mais tempo para chegar nas periferias e regiões mais pobres, como é majoritariamente destinado ao trabalhador formal e assalariado. Em Medelín, segunda maior cidade da Colômbia, o pronto atendimento de um renda mínima para população carente, registrada previamente à epidemia por um aplicativo, permitiu rapidamente mapear esta população e fornecer a renda prontamente, garantindo o sucesso da implementação do distanciamento físico para mitigação da COVID-1931. No Brasil, a existência do Cadastro Único foi um fator acelerador para que o auxílio emergencial aprovado pelo Congresso Nacional, pudesse chegar mais rapidamente a parcelas necessitadas da população ${ }^{32}$. No entanto, devido a uma série de falhas operacionais, grande parcela dessa população tem precisado se expor à grandes aglomerações em filas de bancos e casas lotéricas para recebimento do auxílio ${ }^{33}$.

A análise comparativa realizada com os estados mostrou que vários estados nordestinos compartilham fatores que poderiam amplificar a epidemia, como a densidade urbana, alta desigualdade, altas taxas de informalidade no trabalho, presença de aeroporto internacional e serem destinos interno de turismo. Embora essas características ajudem a explicar uma parte do padrão de distribuição da COVID-19, não fornece explanações mais convincentes para o quadro apresentado. Possivelmente, um dos problemas que agravou a ocorrência da COVID-19 no 
Nordeste foi a precocidade da entrada do vírus na região, neste caso, no estado do Ceará. Apesar das autoridades desse estado terem lançado um conjunto tecnicamente sólido e efetivo de ações preventivas desde o início em que se detectou os primeiros casos, este estado teve o maior número de casos relatados da COVID-19. Investigação retrospectiva de casos de Síndrome Respiratória Aguda Grave, realizada pela vigilância epidemiológica do estado e da Secretaria de Saúde de Fortaleza, mostrou que 50 casos de COVID-19 haviam sido confirmados na capital um dia após a notificação de Wuhan à OMS em janeiro ${ }^{34}$. Outro estudo genético sobre a evolução e disseminação da epidemia de SARS-CoV-2 no país mostrou que três diferentes cepas conseguiram se disseminar no Brasil, e que foram transmitidas antes da confirmação dos primeiros casos oficiais ${ }^{35}$. Uma das cepas atingiu, em maior intensidade, alguns estados na região Sudeste, incluindo São Paulo e Rio de Janeiro; as outras duas entraram no país pelo estado do Ceará, provavelmente vindas da Europa e dos Estados Unidos ${ }^{35}$. As consequências deste processo, desconhecido na época, foi a ampla e silenciosa disseminação do SARS-CoV-2 no país, sem que nenhuma medida de mitigação fosse adotada ${ }^{36}$. Quando os governos dos estados da região Nordeste tomaram as primeiras medidas de distanciamento social para mitigação da epidemia, em meados de março, época em que os primeiros casos foram notificados oficialmente, $\mathrm{o}$ Ceará, por exemplo, já tinha, de fato, 1.160 casos confirmados por COVID-19, e cerca de 1/3 dos municípios do interior já apresentavam $\operatorname{casos}^{34}$. A situação do Ceará, não representa o fracasso das mediadas de distanciamento social adotadas, pois existem evidências de que sem estas medidas a situação seria ainda muito mais grave, com maior número de casos e óbitos. Porém, está relacionada a uma fragilidade do nosso sistema de vigilância epidemiológica que não teve acesso aos primeiros casos de COVID-19 ocorridos em Fortaleza e outras partes do Estado. Por terem ocorrido em pessoas das classes mais altas, entraram pelo sistema privado, não gerando informação ao sistema de vigilância epidemiológica ${ }^{24}$.

Um importante conjunto de medidas para restringir a circulação de pessoas e, consequentemente, diminuir a propagação da epidemia, diz respeito a medidas de fechamento do comércio e de serviços não essenciais, fechamento de escolas, bem como limitação da circulação de pessoas dentro de bairros e entre municípios do estado. Observamos em maior ou menor grau redução da mobilidade social e uma desaceleração na progressão da epidemia em todos os estados do Nordeste. Entretanto, o número de reprodução efetivo permanecia acima de 1 em todos os estados, indicando que a epidemia ainda continuava em crescimento.

Ao mesmo tempo que a epidemia entrou, na maioria dos estados, através de suas capitais e da população mais abastada, depois de estabelecida a transmissão comunitária nestas cidades, rumou para o interior dos estados, muito mais fragilizados que as capitais. Os números de casos acumulados em todas as capitais da região, nesta data, são menores do que o total do interior dos estados. O Rt calculado para cada estado está sendo influenciado fortemente pelo crescimento dos casos do interior. A falta de assistência de nível terciário no municípios interioranos, especialmente no que diz respeito ao percentual de leitos de UTI por habitante, de profissionais da saúde com qualificação no manejo de pacientes internados nestas unidades e dificuldade de acesso da população a estas unidades mostra a maior situação de fragilidade à COVID-19 no interior dos estados. Ao mesmo tempo, na falta de outras medidas a serem executadas neste momento, $\mathrm{o}$ conjunto de medidas centradas no distanciamento social efetivo, tal como o bloqueio total ou lockdown, pode ser a única maneira de reduzir de fato a transmissão da COVID-19 ${ }^{14}$.

Os dados disponíveis não permitem uma análise mais detalhada do distanciamento social em regiões ou bairros de maior e menor poder aquisitivo, bem como os bairros mais distantes das áreas centrais das capitais do Nordeste. Entretanto, um estudo sorológico nacional mostra cidades no Norte com prevalências de mais de $20 \%$, e no Nordeste do país com cerca de $15 \%$, enquanto que outras regiões mais desenvolvidas apresentam taxas próximas de $1 \%{ }^{9}$. O inquérito realizado na capital do Ceará, Fortaleza, também expõe o resultado da enorme desigualdade vivenciada nos grandes centros urbanos. Mostra que bairros mais pobres tiveram quase que um quarto da sua população afetada pela COVID-19, enquanto que os bairros mais ricos, de onde vieram os primeiros casos, tiveram 6 vezes menos, ficando na faixa de $4 \%{ }^{37}$.

A pobreza e a desigualdade marcantes do Nordeste, associadas às demais condições socioeconômicas e culturais da região, fornecem pistas do porquê do quadro da COVID-19 estar sendo tão intenso e disseminado. Por outro lado, o fato de que ações de mitigação foram tomadas precocemente, tão logo os primeiros casos foram reconhecidos, fez com que os efeitos da pandemia 
tenham sido amenizados. Apesar das respostas terem sido bastante distintas pelos estados, dada a ausência de medidas centralizadas emanadas do governo federal, houve uma importante redução no número de óbitos pela COVID-19 na região, como resultado das medidas de distanciamento físico e de ações na saúde tomadas pelos governos estaduais.

A epidemia da COVID-19 atingiu um dos países mais desiguais do mundo, agravando uma crise política, econômico e social sem precedentes que antecedeu a entrada da epidemia. $\mathrm{O}$ quadro recente da COVID-19 no Nordeste brasileiro permite afirmar que várias epidemias estão ocorrendo simultaneamente. É provável que haja novas ondas tanto nas capitais como no interior. E este quadro deve permanecer até que surja uma medida medicamentosa, como a vacina, ou a população atinja, depois de algumas ondas, níveis de "imunidade de rebanho", ou sejam implementadas medidas mais radicais que acompanhem o distanciamento físico, tais como: renda prolongada para famílias vulneráveis, teste em massa, isolamento dos confirmados, com oferta de locais onde possam realizar o isolamento quando o mesmo não for possível (hotéis, escolas, entre outros) e rastreamento dos contatos, medidas estas que não têm sido praticadas nos níveis necessários para cessar ou reduzir significativamente a doença. A epidemia da COVID-19 no nordeste brasileiro, que atinge a região e o país em um dos períodos mais difíceis de sua história política, econômica e social, deixará marcas para sempre no futuro de suas gerações.

\section{Colaboradores}

L Kerr, C Kendall, AAM Silva, EML Aquino, MY Ichihara e ML Barreto: concepção, organização, análise de dados, redação e edição. JM Pescarini: organização, análise de dados, redação e edição. RLF Almeida, TVB Araújo e MFPM Albuquerque: análise de dados e redação. JF Oliveira, C Teles, DCP Jorge, DB Miranda Filho, G Santana, L Gabrielli, R Souza e WV Souza: análise de dados. N Almeida Filho e CMT Marteli: edição. NJ Silva e RAA Ximenes: análise de dados e edição. SP Brandão Filho: organização e análise de dados. 


\section{Referências}

1. Centro de Integração de Dados e Conhecimentos para Saúde (CIDACS). Fiocruz. UFBA. Painel Rede CoVida 2020 [Internet]. [acessado 2020 Jun 20]. Disponível em: https://painel.covid19br.org/

2. Ahmed F, Ahmed NE, Pissarides C, Stiglitz J. Why inequality could spread COVID-19. Lancet Public Health 2020; 5(5):e240.

3. Dolce J, Fonseca B. Desigualdade social é fator de risco para mortes de crianças e adolescentes por Covid-19 no país 2020 [Internet]. Pública Agência de Jornalismo Investigativo; 2020 [acessado 2020 Jun 20]. Disponível em: https://apublica.org/2020/06/desigualdade-social -e-fator-de-risco-para-mortes-de-criancas-e-adolescentes-por-covid-19-no-pais/\#.XuiTr59onPV.face book

4. Sumner A, Hoy C, Ortiz-Juarez E. Estimates of the Impact of COVID-19 on Global Poverty. UNU-WIDER 2020; 800-809.

5. Mahler DG, Lakner C, Aguilar RAC, Wu H. Updated estimates of the impact of COVID-19 on global poverty [Internet]. World Bank; 2020 [acessado 2020 Jun 20]. Disponível em: https://blogs.worldbank.org/opendata/ updated-estimates-impact-covid-19-global-poverty

6. Goes EF, Ramos DO, Ferreira AJF. Desigualdades raciais em saúde e a pandemia da Covid-19. Trab Educ Saude 2020; 18(3):e00278110.

7. Alon TM, Doepke M, Olmstead-Rumsey J, Tertilt M. The impact of COVID-19 on gender equality. NBER Working Papers 2020; 26947.

8. Wenham C, Smith J, Morgan R. COVID-19: the gendered impacts of the outbreak. Lancet 2020; 395(10227):846-848.

9. Hallal P, Hartwig F, Horta B, Victora GD, Silveira M, Struchiner C, Vidaletti LP, Neumann N, Pellanda LC, Dellagostin OA, Burattini MN, Menezes AM, Barros FC, Barros AJ, Victoria CG. Remarkable variability in SARS-CoV-2 antibodies across Brazilian regions: nationwide serological household survey in 27 states. medRxiv 2020; [preprint].

10. Lewnard JA, Lo NC. Scientific and ethical basis for social-distancing interventions against COVID-19. Lancet Infect Dis 2020; 20(6):631.

11. World Health Organization (WHO). Water, sanitation, hygiene and waste management for COVID-19: technical brief, 03 March 2020. Geneva: WHO; 2020.

12. Eikenberry SE, Mancuso M, Iboi E, Phan T, Eikenberry K, Kuang Y, Kostelich E, Gumel AB. To mask or not to mask: Modeling the potential for face mask use by the general public to curtail the COVID-19 pandemic. Infect Dis Model 2020; 5:293-308.

13. Stutt RO, Retkute R, Bradley M, Gilligan CA, Colvin J. A modelling framework to assess the likely effectiveness of facemasks in combination with 'lock-down'in managing the COVID-19 pandemic. Proceedings Royal Society A 2020; 476(2238):20200376.

14. Aquino EM, Silveira IH, Pescarini JM, Aquino R, Souza-Filho JA. Medidas de distanciamento social no controle da pandemia de COVID-19: potenciais impactos e desafios no Brasil. Cien Saude Colet 2020; 25:24232446.

15. Brasil. Instituto Brasileiro de Geografia e Estatística (IBGE). Painel de Indicadores [Internet]. 2020 [acessado 2020 Jun 20]. Disponível em: https://www.ibge.gov. br/indicadores.
16. Cotta W. COVID-19 in Brazil 2020 [Internet]. [acessado 2020 Jun 20]. Disponível em: https://wesleycota. com/

17. Centro de Integração de Dados e Conhecimentos para Saúde (CIDACS). Fiocruz. UFBA. CoVida: Ciência, Informação e Solidariedade [Internet]. 2020 [acessado 2020 Jun 20]. Disponível em: https://covid19br.org/

18. Fundação Oswaldo Cruz (Fiocruz). Painel Infogripe: Monitoramento de casos reportados de sindrome respiratória aguda grave (SRAG) hospitalizados. Rio de Janeiro: Fiocruz; 2020.

19. Brasil. Agência Nacional de Aviação Civil (ANAC). Setor Regulado. Microdados [Internet]. 2020 [acessado 2020 Jun 7]. Disponível em: https://www.anac.gov.br/ assuntos/setor-regulado/empresas/envio-de-informacoes/microdados

20. Google LLC. Google COVID-19 Community Mobility Reports 2020 [Internet]. [acessado 2020 Jun 7]. Disponível em: https://www.google.com/covid19/ mobility/

21. Inloco. Mapa brasileiro da COVID-19 2020 [Internet]. [acessado 2020 Jun 7]. Disponível em: https://www. inloco.com.br/

22. Elliot M, Fairweather I, Olsen W, Pampaka M. A dictionary of social research methods. Oxford: Oxford University Press; 2016.

23. Eggan F. Social Anthropology and the Method of Controlled Comparison. American Anthropologist 1954; 56(5):743-763.

24. Jorge DC, Rodrigues MS, Silva MS, Cardim LL, Silva NB, Silveira IH, Silva VAF, Pereira FAC, Pinho STR, Andrade RFS, Ramos PIP, Oliveira JF. Assessing the nationwide impact of COVID-19 mitigation policies on the transmission rate of SARS-CoV-2 in Brazil. medRxiv 2020; [preprint].

25. Oliveira JF, Jorge DC, Veiga RV, Rodrigues MS, Torquato MF, Silva NB, Fiaconne RL, Castro CP, Paiva ASS, Cardim LL, Amad AAS, Lima EABF, Souza DS, Pinho STR, Ramos PIP, Andrade RFS, Rede CoVida Modelling Task-force. Evaluating the burden of COVID-19 on hospital resources in Bahia, Brazil: A modelling-based analysis of 14.8 million individuals. medRxiv 2020; [preprint].

26. Bastos LS, Niquini RP, Lana RM, Villela DA, Cruz OG, Coelho FC, Codeço CT, Gomes MFC. COVID-19 e hospitalizações por SRAG no Brasil: uma comparação até a 12a semana epidemiológica de 2020. Cad Saúde Pública 2020; 36:e0070120.

27. Trindade E. Os circuitos dos ricos e famosos que disseminaram coronavírus no Brasil. Folha de São Paulo; 2020.

28. Burström B, Tao W. Social determinants of health and inequalities in COVID-19. Eur J Public Health 2020; ckaa095.

29. Patel AP, Paranjpe MD, Kathiresan NP, Rivas MA, Khera AV. Race, Socioeconomic Deprivation, and Hospitalization for COVID-19 in English participants of a National Biobank. medRxiv 2020; [preprint].

30. Brasil. Instituto Brasileiro de Geografia e Estatística (IBGE). Pesquisa Nacional por Amostra de Domicílios Contínua COVID-19. Rio de Janeiro: IBGE; 2020.

31. UOL. Medellín controla vírus com arriscada coleta de dados em massa [Internet]. 2020 [acessado $2020 \mathrm{Jul}$ 10]. Disponível em: encurtador.com.br/mwzEY 
32. Brasil. Governo do Brasil. Assistência Social. Solicitar Auxílio Emergencial (Coronavírus - COVID 19) [Internet]. 2020 [acessado 2020 Jul 10]. Disponível em: https://www.gov.br/pt-br/servicos/solicitar-auxilio-emergencial-de-r-600-covid-19

33. Globo. Agências da Caixa voltam a ter longas filas por problemas com auxílio emergencial [Internet]. Rio de Janeiro: O Globo; 2020 [acessado 2020 Jul 10]. Disponível em: https://gl.globo.com/jornal-nacional/ noticia/2020/07/22/agencias-da-caixa-voltam-a-ter -longas-filas-por-problemas-com-auxilio-emergencial.ghtml

34. Ceará. Secretaria de Saúde. IntegraSUS: transparência da saúde do Ceará Fortaleza [Internet]. 2020 [acessado 2020 Jul 10]. Disponível em: https://integrasus.saude. ce.gov.br/

35. Candido DS, Claro IM, Jesus JG, Souza WM, Moreira FRR, Dellicour S, Mellan TA, Plessis L, Pereira RHM, Sales FCS, Manuli ER, Thézé J, Almeida L, Menezes MT, Voloch CM, Fumagalli MJ, Coletti TM, Silva CAM, Ramundo MS, Amorim MR, Hoeltgebaum HH, Mishra S, Gill MS, Carvalho LM, Buss LF, Prete Jr CA, Ashworth J, Nakaya HI, Peixoto PS, Brady OJ, Nicholls SM, Tanuri A, Rossi ÁD, Braga CKV, Gerber AL, Guimarães APC, Gaburo Jr N, Alencar CS, Ferreira ACS, Lima CX, Levi JE, Granato C, Ferreira GM, Francisco Jr RS, Granja F, Garcia MT, Moretti ML, Perroud Jr MW, Castiñeiras TMPP, Lazari CS, Hill SC, Santos AAS, Simeoni CL, Forato J, Sposito AC, Schreiber AZ, Santos MNN, Sá CZ, Souza RP, Resende-Moreira LC, Teixeira MM, Hubner J, Leme PAF, Moreira RG, Nogueira ML, Brazil-UK Centre for Arbovirus Discovery, Diagnosis, Genomics and Epidemiology (CADDE) Genomic Network, Ferguson NM, Costa SF, Proenca-Modena JL, Vasconcelos ATR, Bhatt $S$, Lemey P, Wu C, Rambaut A, Loman NJ, Aguiar RS, Pybus OG, Sabino EC, Faria NR. Evolution and epidemic spread of SARS-CoV-2 in Brazil. Science 2020; eabd2161.
36. Souza WM, Buss LF, Candido DS, Carrera JP, Li S, Zarebski A, Pereira RHM, Prete Jr CA, Souza-Santos AA, Parag KV, Belotti MCTD, Vincenti-Gonzalez MF, Messina J, Sales FCS, Andrade PS, Nascimento VH, Ghilardi F, Abade L, Gutierrez B, Kraemer MUG, Braga CKV, Aguiar RS, Alexander N, Mayaud P, Brady OJ, Marcilio I, Gouveia N, Li G, Tami A, Oliveira SB, Porto VBG, Ganem F, Almeida WAF, Fantinato FFST, Macário EM, Oliveira WK, Nogueira ML, Pybus OG, Wu C, Croda J, Sabino EC, Faria NR. Epidemiological and clinical characteristics of the early phase of the COVID-19 epidemic in Brazil. Nature Humam Behav 2020; 4:856-865.

37. Ceará. Secretaria da Saúde. Secretaria Municipal de Saúde. Inquérito soroprevalência coronavírus em Fortaleza. Fortaleza: Secretaria da Saúde do Estado do Ceará e Secretaria Municipal de Saúde de Fortaleza; 2020.

Artigo apresentado em 31/07/2020

Aprovado em 10/08/2020

Versão final apresentada em 12/08/2020 